TAPROBANICA, ISSN 1800-427X. April, 2011. Vol. 03, No. 01: pp. 31-37.

(C) Taprobanica Private Limited, Jl. Kuricang 18 Gd.9 No.47, Ciputat 15412, Tangerang, Indonesia.

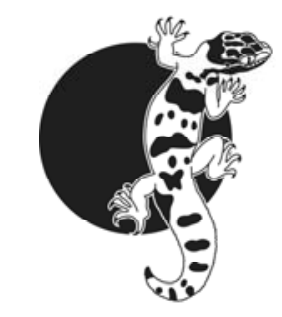

\title{
REPRODUCTION AND SEXUAL DICHROMATISM IN Sitana ponticeriana (REPTILIA: DRACONINAE: AGAMIDAE)
}

Arttatrana Pal ${ }^{1}$, Mitali Madhusmita Swain ${ }^{1}$ and Swapnananda Rath ${ }^{2}$

\footnotetext{
${ }^{1}$ School of Biotechnology, KIIT University, Bhubaneswar, Orissa751024, India; E-mail: arttatrana@yahoo.com

${ }^{2}$ B. J. B. College, Bhubaneswar 751 014, Orissa, India
}

\begin{abstract}
This paper presents the results of a two-year study of the sexual dichromatism, breeding, clutch size and development in a population of Sitana ponticeriana, conducted at Balukhand-Konark Wildlife Sanctuary, Orissa, India. Sexual dimorphism appears as a brighter overall colouration with red and dark blue gular pouch develops as outward projection at the neck. In the breeding season, mature males have crimson-red or brick-red colour at the base of the tail. Lizards start courtship in the early morning and afternoon, depending on the ambient temperature, during the early monsoons. Vitellogenic and gravid females occur simultaneously in early and mid-summer, and lay eggs during the onset of rains. Potentially, 2-3 clutches of 6- 23 eggs (mean $17.39 \pm 4.39 \mathrm{eggs} / \mathrm{clutch}$ ) are produced by each female each year. The smallest gravid female contained more eggs than larger ones. Eggs collected late in the reproductive season were significantly larger than those collected earlier. Freshly laid eggs are elliptical; during development, the shape, size and volume of the eggs were changed; hatchling success observed after 39 days of incubation.
\end{abstract}

Key words: ambient temperature, clutch size, development, Fan-throated lizard, India

\section{Introduction}

Sexual dimorphism is a widespread feature among lizards, as in many other groups of animals (Andersson, 1994). Male and female lizards may differ in many traits, such as colouration, body shape and size, and these differences have been assigned to the effects of sexual selection (Andersson, 1994). However, other mechanisms, such as ecological divergence (Schoener, 1967; Shine, 1991) and fecundity selection (Shine \& Charnov, 1992) offer alternative explanations for sexual dimorphism (Shine, 1979). Asian agamid lizards of the genus Draco shows distinct morphological patterns of sexual dimorphism in body size and wing size investigated by Mori \& Hikida (1992) and Shine et al. (1998). Many of the 
lizards in the Iguanidae, Lacertidae and Agamidae families have complex display behaviors and brightly colored ornaments (Cooper \& Greenberg, 1992; LeBas \& Marshall, 2000). Australian agamids are no exception with widespread sexual dichromatism (Cooper \& Greenberg, 1992), territoriality and highly visually oriented behaviour (Greer, 1989).

Information on the breeding biology of Indian Agamid lizards is sparse. Calotes versicolor breeds during the southwest monsoon from late May to October and as in other lizards, its reproductive sequence comprises renewal, breeding and post breeding phases (Shanbhag, 2002). The males are spermatogenetically active from April-September (Radder et al., 2001) and gravid lizards occur from May-October (Shanbhag, 2002). In individuals with variable clutch patterns, both size and frequency of the clutch may be different depending on the proximate climatic factors, food availability, fat reserves and its maternal body size (Ballinger, 1978). Clutch size in Sceloperous virgatus correlates with environmental factors (Smith et al. 1995). Some previous studies indicate that hatchling size is not always correlated with egg size, and that proximate factors such as nesting site and breeding timing may influence this relationship (Kraemer \& Bennett, 1981; Packard, 1991; Radder et al., 2002). Prolonged oviductal egg retention occurs in several species of oviparous lizards (Brana et al., 1991). In some of them, embryonic development of eggs continues normally during prolonged egg retention and even continues to hatching (Packard et al., 1977). However, some others such as Urosaurus ornatus (Mathies \& Andrews, 1999) arrest development until after oviposition. The garden lizard, Calotes versicolor retains eggs in the oviduct for as long as six months under unfavorable conditions such as a lack of proper oviposition sites or un-optimal rainfall (Shanbhag et al., 2003). The maximum incubation period is 62 days; whereas, under ideal conditions the minimum incubation period is 22 days (Muthukaruppan et al., 1970). Generally, reptilian eggs that incubate at high temperatures hatch earlier than those that incubate at low temperatures (Angilletta et al., 2000; Deeming \& Ferguson 1991). Embryonic development of Calotes versicolor stops below $23^{\circ} \mathrm{C}$ (Radder et al., 2002; Shanbhag et al., 2003). Its eggs have a flexible eggshell and increase in volume after oviposition, with an encroachment in embryonic growth primarily due to infused moisture (Radder et al., 2002).
The fan-throated lizard, Sitana ponticeriana is a medium-sized, ground-dwelling agamid scattered throughout open xeric patches of forest in India (Pal et al., 2010). There are only few studies on the biology of Sitana ponticeriana (Pal et al., 2007; Rajkumar \&Shanbhag, 2003, 2004; Rath \& Pal, 2007) and its reproductive biology remains subject to speculation because of small sample sizes over limited periods of time. Here, we report on sexual dimorphism, breeding, clutch size and development of Sitana ponticeriana over a two-year period.

\section{Materials and methods}

Study area: This study took place on the Balukhand-Konark Wildlife Sanctuary (BKWS) in the District of Puri, Orissa, India $\left(19^{\circ} 48^{\prime}\right.$ to $19^{\circ} 54^{\prime}$ $\mathrm{N}, 85^{\circ} 52^{\prime}$ to $86^{\circ} 14^{\prime} \mathrm{E}$ ) (Pal et al., 2010a). The Sanctuary is a $71.7 \mathrm{~km}^{2}$ area established on a sandy tract along the coast between Puri and Konark. The canopy composition includes mainly Casuarinas sp., Tamarind (Tamarindus indica), Anacardium sp., Karanja (Pongamia glabra), Polanga (Calophyllum inophyllum), Neem (Azadirachta indica), Eucalyptus sp., and Acacia sp. The understory shrubs include Pandanus sp., Adhatoda (Adhatoda vasica), and various horticultural plantings. The lizard fauna includes Lygosoma punctata, Eutropis bibroni, E. macularia and Calotes versicolor. The maximum air temperature is $40^{\circ} \mathrm{C}$ during May-June. Maximum surface soil temperature ranges from $40^{\circ} \mathrm{C}$ in the shade to over $45^{\circ} \mathrm{C}$ in areas with full sun. Minimum winter temperature is $10^{\circ} \mathrm{C}$.

Maintenance in the laboratory: We collected lizards by hand from October 2001 through September 2003 and after an acclimatization period of about 2-7 days in the laboratory; we sexed the specimens by examining the gonads and secondary sexual characteristics. We categorized the lizards as juveniles $(\mathrm{SVL}=15-26 \mathrm{~mm})$, immature $(\mathrm{SVL}=27$ $35 \mathrm{~mm}$ ) and mature adults (SVL $\geq 36 \mathrm{~mm}$ above) including gravid females (Pal et al., 2010a,b). We fed the lizards by Isoptera, Hymenoptera, Orthoptera, Acrididae etc. (Pal et al., 2007) and provided water ad-libidum each day. We collected gravid females of $S$. ponticeriana during the months of May-August (2001 and 2003) exclusively for determining clutch size. We recorded snout-vent length (SVL), taillength (TL) and total length (TOL) for each lizard. We confirmed oviposition following the methods adopted by Shanbhag et al. (2003). Each terrarium contained a few potted plants, dry sticks and leaves, hiding sites, water and a substratum of sandy soil from the capture site. Gravid females were found 
from May to October, consequently, we classified them as early, mid- and late breeders depending on the captured date. After egg laying, we incubated the eggs in moist sandy soil at ambient temperature $\sim 35 \pm 2{ }^{\circ} \mathrm{C}$ ). We did not consider second or third clutches in our study because these developed in the female's body while she was in captivity. After the first clutch, we returned the adult lizards to the sites where we originally captured them. Eggs hatched after 39 days of incubation and $>10 \%$ of eggs hatched for each clutch. We recorded the SVL, TL and TOL of the hatchlings and then released them into the Sanctuary after 2-3 days.

Statistical analysis: We used Chi-square to compare sexual dimorphism and reproductive status between the two years in our study. We identified the reproductive characteristics between early and late in the breeding season with regression analysis. Student's $t$-tests were used when the covariant was not obvious. We presented all of the averages $\pm \mathrm{SE}$ unless otherwise indicated. We used $\alpha=0.01$ for decision theory in all statistical tests.

\section{Results}

Sexual dimorphism and dichromatism: Both sexes were olive-brown above and whitish below neck. The dorsum of body is dark-brown with blackedged diamond-shaped rhomboidal patches in both sexes. The gular pouches of males turned brilliant red and dark blue during the breeding season. Males unfolded and folded their pouches several times to entice females during courtship. During the breeding season the tail of mature males are crimson-red or brick-red; whereas, the females have a brown coloured tail. Immature adult males show a white flap-like structure below the neck. However, the mean of SVL, TL and TOL of 256 mature males were $43.51 \mathrm{~mm} \pm 5.96,90.22 \mathrm{~mm} \pm 12.44$ and $133.63 \mathrm{~mm} \pm 17.95$, respectively. Similarly, the mean of SVL, TL, and TOL of 156 mature females were $43.96 \mathrm{~mm} \pm 6.82,84.26 \mathrm{~mm} \pm 12.44$ and $128.21 \mathrm{~mm} \pm 17.98$, respectively. The $t$-values between SVL, TL and TOL of the males and females were $0.69,4.69$ and 2.95 respectively and were significant at $1 \%$ level (Table 1). The regression equation of males and the females were $\mathrm{TL}=1.637 \mathrm{SVL}+0.0072$ and $\mathrm{TOL}=2.5793 \mathrm{SVL}$ +0.0248 and $\mathrm{TL}=1.7392 \mathrm{SVL}+0.8364$ and TOL $=2.7864 \mathrm{SVL}+0.6843$ respectively $($ Fig. 1a,b,c,d)

Breeding: Sitana ponticeriana breed from premonsoon through post-monsoon periods (May to September). The peak breeding season was from June through July, but occasionally, an early or late monsoon stimulated breeding as early as the end of April or as late as September, was recorded. This species required some form of weather conditions such as minimum amount of rainfall and ambient temperature should be $<40^{\circ} \mathrm{C}$ before breeding. The maximum number of mature males and the gravid females appeared in April through July. During an early monsoon several mating pairs of the species were active in the field from April through August, but the breeding males were more active than the females. Lizards start courtship in the early morning and afternoon, depending on the ambient temperature, and high ambient temperatures at midday appeared to preclude mating during that time. Interestingly, sometimes mating has been observed throughout the day, on cloudy days.

Clutch size: We collected all the adult lizards $(n=$ 86) during October 2001 through September 2003. Lizards were reproductively active as obvious by the presence of either vitellogenic follicles or oviductal eggs or both. The SVL of the smallest female with oviductal eggs was $37 \mathrm{~mm}$, and that of the largest, $58 \mathrm{~mm}$. Clutch size averaged $17.39 \pm$ 4.39 (Table 2) and varied from 6-23 eggs (Fig. 2). Maternal SVL and clutch size was not positively correlated. There was no significant relationship between egg mass and clutch size. Early clutches were larger than those from later clutches.

Development: Lizards exhibit prolonged oviductal egg retention when oviposition sites, certain proximate like high ambient temperature and lack of rain falls affect egg-laying behaviour. The egg retention was systematically studied under laboratory condition. The lizards held eggs in their oviducts for about three to four weeks before oviposition. However, their reproductive output was dependent on the climatic factors (e.g., rainfall) that they normally experienced in the wild. We observed in our terrarium, that oviposition was not fixed in a particular place rather it was here and there. It took 10-20 minutes to complete and some lizards (60\%) even took 30-45 minutes (2\%) even took 30-45 minutes. We found 6-8 eggs in the terrarium that we immediately measured (Table 2), and then placed them under incubation. The eggs were oval or elliptical with flexible shells and coloured white. We measured the length and breadth of those eggs that had not died after 25-32 days of oviposition. Egg volumes increased with embryonic growth up to 32 days. We removed some eggs after 32 days of incubation and observed the growth stage of the lizard. Successful hatching occurred after 39 days of incubation. 


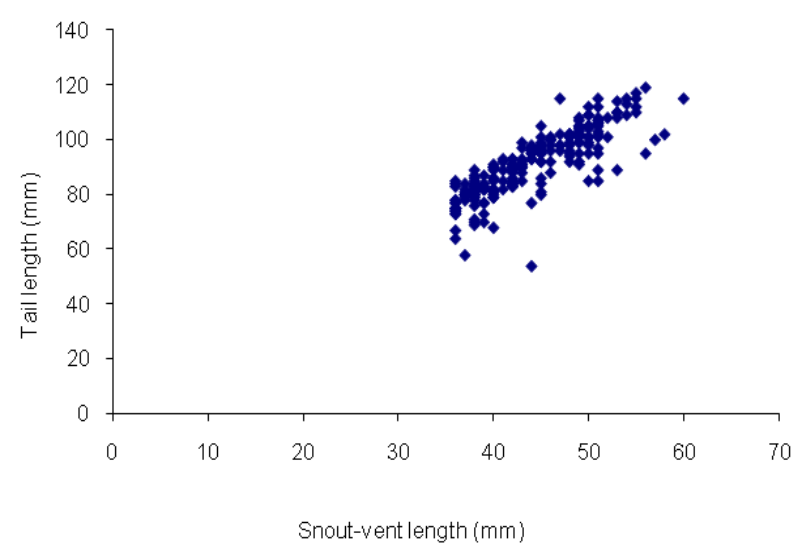

Fig. 1a: (A) Plot of TLagainst SVL of mature male Sitana ponticeriana at BKWS

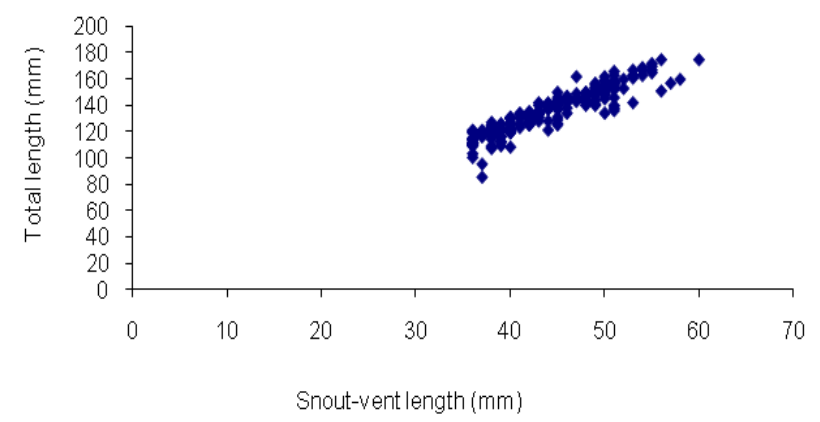

Fig. 1b: Regression curves of TOL against SVL of mature male Sitana ponticeriana at BKWS

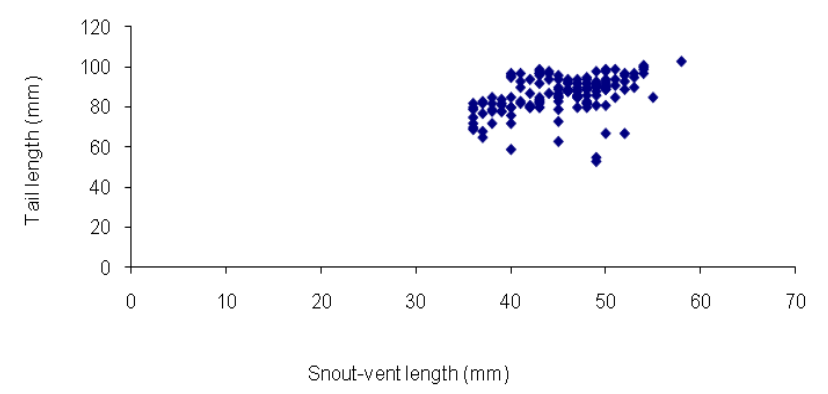

Fig. 1c: Regression curves of TL against SVL of mature female Sitana ponticeriana at BKWS

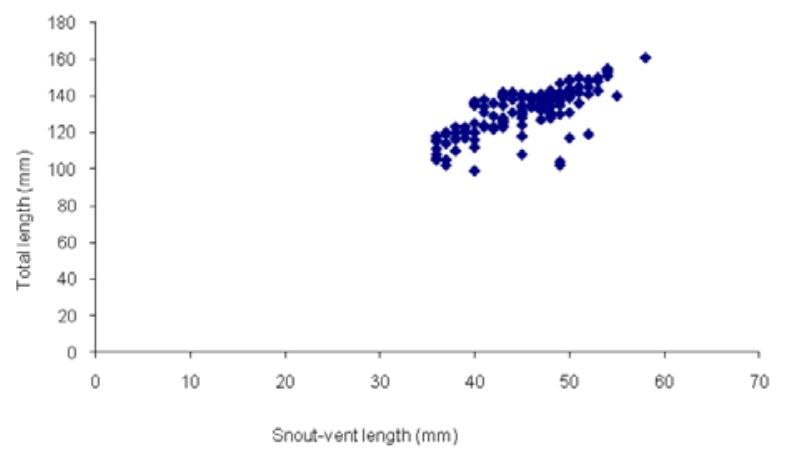

Fig. 1d: Regression curves of TOL against SVL of mature female Sitana ponticeriana at BKWS

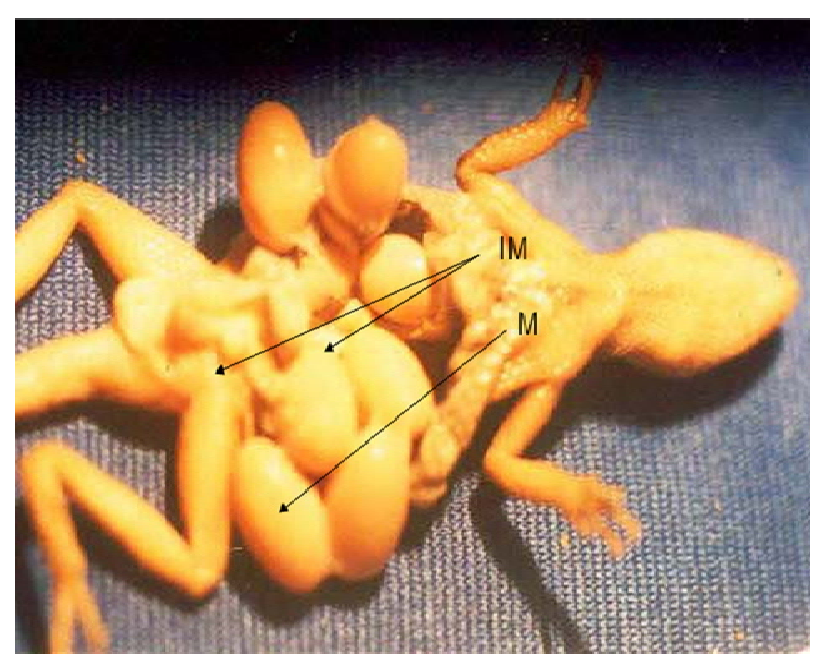

Fig. 2: Mature (M) and immature (IM) eggs of dissected gravid Sitana ponticeriana (SVL: 49mm) from BKWS

\section{Discussion}

The evidence for female choice in lizards is at best equivocal (Olsson \& Madsen, 1998) and many taxa display remarkable sexual dichromatism with males of many species having ornaments such as rostral horns, dewlaps, gular sacs and crests. This is true of agamids, chamaeleons and their New World sister group, the iguanids. Colour patches may serve as badges of status among males and can affect the outcome of male contests in some species (Olsson \& Madsen, 1998). Here, Sitana ponticeriana showed a distinctive red and dark blue gular pouch developed under the neck of male that they used to attract female lizards during the breeding season using the crimson red colour at the base of tail. For instance, there is evidence that size dimorphism may be associated with territoriality, social polygyny and male-male competition in lizards (Olsson \& Madsen, 1998; Stamps, 1983). Size dimorphism in lizards can reflect ecological resource partitioning (Magurran, 1998; PerezMellado \& de la Riva, 1993; Shine, 1979). Our study suggests a negative association between size dimorphism that may reflect mechanisms other than intersexual selection (female choice) in Sitana ponticeriana.

Many previous publications reported the clutch sizes of Calotes versicolor (Erdelen, 1986; Rout \& Ghosh, 1984). The present study on the clutch size of $S$. ponticeriana confirms some previous reports, but contradicts others. Clutch size was larger in our study than in previous reports. Subba Rao \& Rajabai (1972) reported that these lizards produce $8-13$ eggs with a mean value of 11.2 eggs/clutch ( $n$ $=10$ clutches, SVL range $36-52 \mathrm{~mm}$ ), but Tikader \& Sharma (1992) reported 11-14 eggs/clutch. 
According to Rajkumar \& Shanbhag (2003) the clutch size varies from 7-19 with a mean value of 15.47. In our study, clutch size varied from 6-23 eggs per clutch, but a mean value of $17.39(n=88$ clutches) was noted. The smaller clutch sizes reported in the previous studies may stem from smaller females, geographic variation, or other environmental factors that regulate clutch size. However, clutch size did not differ between the two years of our study.

Clutch size of $S$. ponticeriana was not increased with maternal SVL, and there was no evidence of any relationship between maternal SVL and egg size. Further, the lack of an inverse correlation between clutch size and egg size suggests that there was no trade-off between these two reproductive traits, implying that there is optimization of egg size. This species produces at least two to three clutches in a breeding season. The early clutches are larger than the later ones as reported in other species of lizards (Shanbhag, 2002, 2003). Decrease in clutch size results from a trade-off between egg size and clutch size (i.e., larger eggs, but few in number) where food availability and modes of energy allocation exist in several species of lizards (Shanbhag, 2003).
The present study on development of $S$. ponticeriana occurred over 30-39 days in captivity. This species shows polyautochrony because it ovulates many eggs simultaneously from both of its ovaries as also seen in garden lizard (Radder et al., 2001). Eggs of S. ponticeriana increase in volume with embryonic growth following oviposition. The increase in the size of eggs is due to infused moisture (Shanbhag et al., 2003). Further, we speculate that arresting embryonic growth also lessens physiological demands for oxygen and moisture needed by the growing embryo. Shanbhag et al. (2003) demonstrated that embryonic diapauses during prolonged egg retention occurred in Calotes versicolor when its body temperature is lowered by $3-5^{\circ} \mathrm{C}$.

Our investigation supports the ambient temperature and rainfall, both which influence the amount of food that increasing energy available for reproduction of this species. Further, low temperature, cloudy skies and wet conditions may interfere with lizard thermal ecology but interestingly, these characters strengthening the reproductive behaviour also resulting in complex interactions with life history of this subtropical lizard.

Table 1: Summary of the sexual dimorphism traits in mature male $(\mathrm{N}=256)$ and female $(\mathrm{N}=156)$ of Sitana ponticeriana at BKWS, Orissa, India from September 2001-October 2003.

\begin{tabular}{cccc}
\hline & SVL \pm SD $(\mathbf{m m})$ & TL \pm SD $(\mathbf{m m})$ & TOL \pm SD $(\mathbf{m m})$ \\
\hline Male & $43.51 \mathrm{~mm} \pm 5.9$ & $90.22 \pm 12.44$ & $133.63 \pm 17.95$ \\
Female & $43.96 \pm 6.82$ & $84.26 \pm 12.44$ & $128.21 \pm 17.98$ \\
t-Test & 0.69 & 4.69 & 2.95 \\
\hline
\end{tabular}

$\# \alpha=0.01$

Table 2: Summary of the recorded traits in Sitana ponticeriana at BKWS, Orissa, India from September 2001-October 2003

\begin{tabular}{lcc}
\hline Variable & Mean \pm SD & Range \\
\hline Maternal SVL (mm) & $46.68 \pm 6.38$ & $37-58$ \\
Clutch size (n) & $17.39 \pm 4.39$ & $6-23$ \\
Egg mass (mg) & $0.11 \pm 0.01$ & $0.08-0.13$ \\
Egg length (mm) & $9.87 \pm 1.33$ & $8-11$ \\
Egg width (mm) & $5.04 \pm 0.75$ & $4-6$ \\
Offspring SVL (mm) & $13.8 \pm 2.47$ & $13-15$ \\
Offspring TL (mm) & $26.6 \pm 1.06$ & $25-28$ \\
Offspring TOL (mm) & $40.4 \pm 0.89$ & $38-43$ \\
\hline
\end{tabular}


Acknowledgements: We are grateful to Ulrich Manthey, Natalia Ananjeva and John Rudge for reviewing the manuscript and Ajay K Patra (Utkal University, Orissa) for providing laboratory facilities.

\section{Literature cited}

Anderson, R. A., 1994. Functional and population responses of the lizard, Cnemidophorus tigris to environmental fluctuations. American Zoologist, 34: 409-421.

Angilletta, M. J. Jr., R. S. Winters, and A.E. Dunham, 2000. Thermal effects of the energetic of lizard embryos: implications for hatchling phenotypes. Ecology, 81: 2957-2968.

Ballinger, R. E., 1978. The vertebrate ovary. In: Comparative Biology and Evolution. Jones, R.E. (Ed.). Plenum Press, New York, USA: 789-825.

Brana, D., A. Bea, and J.M. Arrayago, 1991. Egg retention in lacertid lizards: relationship with reproductive ecology and the evolution of viviparity. Herpetologica, 47: 218-226.

Cooper, W. E., and N. Greenberg, 1992. Reptilian coloration and behaviour. In: Biology of the Reptilia. Gans. C. (Ed.). University of Chicago Press, USA, Vol. 18: 298-422.

Deeming, D. C., and M. W. J. Ferguson, 1991. Physiological effects of incubation temperature on embryonic development in reptiles and birds. In: Egg incubation, its effects on embryonic development in birds and reptiles. Deeming, D.C., and M.W.J. Ferguson (Eds.). Cambridge University Press, Cambridge: 147-171.

Erdelen, W., 1986. The genus Calotes (Sauria: Agamidae) in Sri Lanka: clutch size and reproductive seasonality of Calotes versicolor- preliminary results. Spixiana, 9: 111-115.

Greer, A. E., 1989. The biology and evolution of Australian lizards. Chipping Norton, Australia: Surrey Beatty \& Sons.

Kraemer, J. E., and S. H. Bennett, 1981. Utilization of posthatching yolk in loggerhead sea turtles, Caretta caretta. Copeia, 1981: 406 - 411.

Magurran, A. E., 1998. Population differentiation without speciation. Philosophical Transactions of the Royal Society of London Series B 353: 275-286.
Mathies, T., and R. M. Andrews, 1999. Determinants of embryonic stage at oviposition in the lizard Urosaurus ornatus. Physiological and Biochemical Zoology, 72: 645-655.

Mori, A., and T. Hikida, 1992. A preliminary study of sexual dimorphism in wing morphology of the species of the flying lizards, genus Draco. Japanese Journal of Herpetology, 14: 178-183.

Muthukkaruppan, V., P. Kanakambika, V. Manickavel, and K. Veeraraghavan. 1970. Analysis of the development of the lizard, Calotes versicolor. A series of normal stages in the embryonic development. Journal of Morphology, 130: 479-490.

LeBas N. R. and N. J. Marshall, 2000. The role of colour in signalling and male choice in the agamid lizard Ctenophorus ornatus. Proceedings of the Royal Society B 267: 445-452.

Olsson, M., and T. Madsen, 1998. Sexual selection and sperm competition in reptiles. In: Sperm competition and sexual selection. Birkhead, T. R. and A. P., Moller (Eds.). London, Academic Press, London: 503-577

Packard, G. C., 1991. Physiological and ecological importance of water to embryos of oviparous reptiles. In: Egg incubation: its effects on embryonic development in birds and reptiles. Deeming, D. C., and M. W. J. Ferguson (Eds.). Cambridge, Cambridge University press, Cambridge: $213-228$.

Packard, G. C., R. C. Tracy, and J. J. Roth, 1977. The physiological ecology of reptilian eggs and embryos, and the evolution of viviparity within the class reptilia. Biological Reviews, 52: 71-105.

Pal, A., M. M., Swain, and S. Rath, 2007. Seasonal variation in the diet of the fan-throated lizard, Sitana ponticeriana (Sauria: Agamidae). Herpetological Conservation and Biology, 2: 145-148.

Pal, A., M. M., Swain, and S. Rath, 2010a. Growth and demography of the fan-throated Sitana ponticeriana (Sauria: Agamidae) from a tropical environment in India. Herpetological Bulletin, 111: 25-35.

Pal, A., M. M., Swain, and S. Rath, 2010b. Observation on microhabitat use and activity patterns in Sitana ponticeriana (Sauria: Agamidae). Russian Journal of Herpetology, 17(1): 22-30.

Perez-Mellado, V., and I. de la Riva, 1993. Sexual size, dimorphism and ecology: the case of a tropical 
lizard, Tropidurus melanopleurus (Sauria: Tropiduridae). Copeia, 1993: 969-976.

Radder, R. S., B. A. Shanbhag, and S. K. Saidapur, 2001. Pattern of plasma sex steroid hormone levels during reproductive cycles of male and female tropical lizard, Calotes versicolor. General and Comparative Endocrinology, 124: 285-292.

Radder, R. S., B. A. Shanbhag, and S. K. Saidapur, 2002. Influence of incubation temperature and substrate on eggs and embryos of the garden lizard, Calotes versicolor (Daud.). Amphibia-Reptilia, 23: $71-82$.

Rajkumar, S. R., and B. A. Shanbhag, 2003. Interrelationships among reproductive traits of female lizard, Sitana ponticeriana (Cuvier). Current Science, 85: 89-91.

Rajkumar, S. R., and B. A. Shanbhag, 2004. Factors influencing offspring traits in the oviparous multiclutched lizard, Calotes versicolor (Agamidae). Journal of Bioscience, 29: 105-110.

Rath, S., and A. Pal, 2007. Age determination in Fanthroated Lizard, Sitana ponticeriana (Cuvier). Indian Journal of Gerontology, 21: 1-8.

Rout, S. K., and K. C. Ghose, 1984. Nesting and egg laying behavior of the garden lizard (Calotes versicolor). Herpetological Review, 15: 108.

Schoener, T. W., 1967. The ecological significance of sexual dimorphism in size in the lizard Anolis conspersus. Science, 155: 474-477.

Shanbhag, B.A. 2002. Reproductive biology of Indian reptiles. Proceedings of the Indian National Science Academy, 68: 497-528.

Shanbhag, B. A., 2003. Reproductive strategies in the lizard, Calotes versicolor. Current Scienc,e 84: 646652.

Shanbhag, B. A., R. S. Radder, and S. K Saidapur, 2002. Members of opposite sex mutually regulate gonadal recrudescence in the lizard Calotes versicolor (Agamidae). Journal of Bioscience, 27: 529-537.

Shanbhag, B. A., K. Srinivas, S. Rajkumar, and S. Radder, 2003. Lowering body temperature induces embryonic diapause during prolonged egg retention in the lizard, Calotes versicolor. Naturwissenschaften, 90: 33-35.
Shine, R., 1979. Sexual selection and sexual dimorphism in the Amphibia. Copeia, 1979: 297-306.

Shine, R., 1991. Australian Snakes: A Natural History. Cornell. University Press, Ithaca, New York: 223.

Shine, R. and E. L. Charnov, 1992. Patterns of survival, growth, and maturation in snakes and lizards. American Naturalist, 139: 1257-1269.

Shine, R., S. Keogh, P. Doughty, and H. Giragossyan, 1998. Costs of reproduction and the evolution of sexual dimorphism in a flying lizard Draco melanopogon (Agamidae). Journal of Zoology London, 246: 203-213.

Smith G. R., R. E. Ballinger, and B. R. Rose, 1995. Reproduction in Sceloporus virgatus from the Chiricahua Mountains of Southeastern Arizona with emphasis on annual variation. Herpetologica, 51: 342349.

Stamps, J. A., 1983. Sexual selection, sexual dimorphism and territoriality. In: Lizard Ecology, Studies of a Model Organism. Huey, R. B., E. R Pianka and T. W. Schoener (Eds.). Harvard University Press, Cambridge, Massachusetts, USA: 169-204

Subba Rao, M. V., and B. S. Rajabai, 1972. Reproduction in the ground lizard, Sitana ponticeriana and the garden lizard, Calotes nemoricola. British Journal of Herpetology, 4: 245251.

Tikader, B. K., and R. C. Sharma, 1992. Handbook of Indian Lizards, Director, Zoological Survey of India, (Eds.). ZSI, Calcutta, India. 